\title{
SCIDiC
}

\author{
International Journal of Dentistry and Oral Science (IJDOS) \\ ISSN: 2377-8075
}

\section{Evaluation of Sexual Dimorphism in Maxillary Right First and Second Molars and Mandibular Left Canine in Syrians}

Research Article

Aljaber Abo Fakher $\mathrm{MG}^{1}$, Al-Assaf $\mathrm{M}^{2 *}$, Abdul-Hak $\mathrm{M}^{1}$, Hamadah $\mathrm{O}^{1}$, Nofal $\mathrm{H}^{3}$

${ }^{1}$ Department of Oral Medicine, Faculty of Dentistry, Damascus University, Damascus, Syria.

${ }^{2}$ Department of Oral Histology and Pathology, Faculty of Dentistry, Damascus University, Damascus, Syria.

${ }^{3}$ Department of Forensic Medicine, Faculty of medicine, Damascus University, Damascus, Syria.

\section{Abstract}

\begin{abstract}
Introduction: Sex determination is an important step in establishing the biological profile of unidentified human remains in forensic science. Tooth size variations have been reported among sexes and different populations.

Aim: The aim of this study is to assess the sex of unknown skeletonized or decomposed human remains in Syria using metrical measurements on teeth.

Materials and Methods: The sample involved 266 individuals from Syrian population (137 female,129 male) aged 18-22 years. mesiodistal widths of left mandibular canines, Buccolingual and mesiodistal widths of first and second upper right molars were measured on gypsum casts with help of digital vernier caliper. These parameters were subjected to different analysis using SPSS 20.0 software. Kolmogorov-Smirnov test showed that data were normally distributed, then the parameters were analyzed by t-test for independent samples. And LRA for predicting accuracy percentage.

Results: All detected parameters in this study showed significant statistical gender difference, mesiodistal width of mandibular canines measurements showed the highest difference, with $(\mathrm{P}<0.001$ _ mean: $7.139 \pm 0.49 \mathrm{~mm}$ for males, $6.519 \pm 0.28$ $\mathrm{mm}$ for females).

Conclusion: The findings support the usefulness of employing odontometric analysis of the canines and first and second upper right molars in gender estimation that lead to identification of unknown person in Syrian population.
\end{abstract}

Keywords: Sex Determination; Identification; Forensic Odontology; Forensic Anthropology.

\section{Introduction}

In legal sciences, the term 'Identification' in general refers to the process of identifying persons and human remains, particularly in the context of fires, vehicle and aircraft crashes and mass disasters as well [1]. Identification of sex in skeletonized and/or heavily decomposed remains is one of the main challenges whose solution contributes to Reaching a positive identification process for the victim, which mainly depends on the completeness of the human remains and sexual dimorphism in physical characteristics that differ between societies [2].

While some studies indicated the possibility of determining sex with an accuracy of up to $98 \%$ from complete bone remains, this percentage is much lower in incomplete human remains, as a result of violent deaths or due to post-mortem environmental conditions [3].

Teeth are the hardest and most chemically stable tissue of the human body, and it is one of the few parts of the human body that can survive and last even in the most extreme environmental conditions [4]. It thus constitutes a fundamental key in forensic anthropological and genetic investigation.

Numerous studies have shown that there are clear differences in inter-ethnic dental sizes, as well as between males and females [5]. Generally, measurements of mesiodistal width (MD), and buccolingual (BL) width of teeth are a good indicator of sex determination.

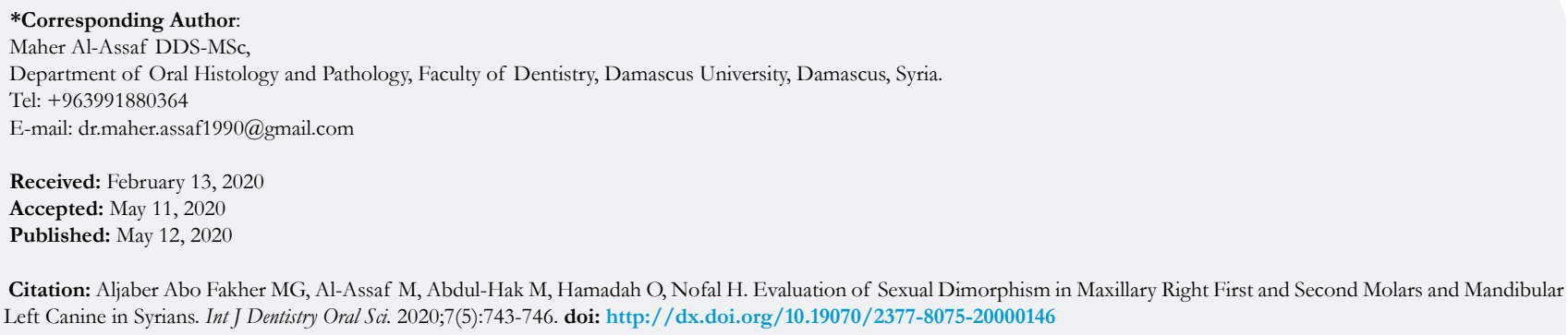


Permanent molars, especially the first ones, are among the important indicators in the investigation of sex, as they emerge in early stages of life, which makes them more important than pelvic indicators [6], which are considered the golden standard in sex identification. As for canines, they are considered to be the most different in their sizes between the two sexes (Sexual Dimorphism). A systematic review study found recently that the lower left and right canines are the most important teeth in determining sex [7]. This study aims to Determine the possibility of using mesiodistal width (MD) of lower left canine, and mesiodistal width (MD) and buccolingual width (BL) of upper right first and second molars as effective indicators in sex identification in Syrian population.

\section{Materials and Methods}

The sample consisted of 300 dental students at the Faculty of Dentistry, Damascus University, all students were Syrians and aged between 18-22 years old. Dental casts were obtained after the following exclusion criteria were applied:

Any person Who suffers from periodontitis, malocclusion, bruxism, attrition, dental caries on upper molars or lower left canine or any one underwent previous orthodontic treatment. 266 pairs of casts were adopted as a final approved sample for this study. The symbol $\mathrm{M}$ was written on the base of all male casts, and the symbol $\mathrm{F}$ on the base of all female casts, and then all casts were mixed together randomly and then numbered.

The MD width was adopted by measuring the distance between the two opposite points (one on the medial surface and the other on the distal surface) measured by digital vernier claiper on the surface of the tooth (molar/canine). Whereas the BL width was the farthest distance between two opposite points (one on the buccal surface and the other on the lingual surface of the molar), all measurements were taken in a well-lit room.

In order to investigate the reliability of the measurements, the measurements were repeated for 20 casts by the main researcher after one month, and the second researcher also repeated the twenty measurements in order to investigate both random errors using ICCs test and systematic error using Paired t-test.

Variables were tested for normal distribution using KolmogorovSmirnov test. Then, each of the five male and female measurements was compared using t-test for independent samples analy- sis. Accuracy of these indicators was then extracted by LRA logistic regression test. The level of significance was set at 0.05. The statistical analysis was performed using the Statistical Package Software for Social Sciences (SPSS), version 20.0 (SPSS Inc., Chicago, IL, USA).

\section{Results}

This study was conducted on 266 individuals (137 female-129 male) aged between 18 and 22 years old. Kolomogrov-Smirnov test showed that the sample was naturally distributed, and t-test test for independent samples showed that all the variables were statistically significant as shown in table (1).

Table (1) shows that the most statistically significant index between males and females is the lower left canine, the mean MD width of the lower left canine in males was $(7.139 \pm 0.49) \mathrm{mm}$, while it was $(6.519 \pm 0.26) \mathrm{mm}$ for females.

As for the results of a logistic regression test LRA, the accuracy of sex prediction in female sample depending only on the canine was $83.9 \%, 79.7 \%$ in male sample, and in the complete sample, it reached $81.9 \%$.

However, for the first and second upper molar indexes, the accuracy of sex prediction for the entire sample ranged from $56.7 \%$ to $63.9 \%$

\section{Discussion}

Teeth are the best parts of the human body that can remain for long periods of time and under various climatic conditions, and the information that the teeth carry in their form, tissues and genetic structures is one of the most valuable information that can be extracted $[3,6,9]$.

Although genetic analyzes of DNA on teeth remain the most reliable in determining sex, the use of these analyzes in difficult situations like armed conflict and mass graves will not be the best choice in identification because of their high cost and other logistical difficulties [9].

Therefore, the importance of this study comes because it sheds light on some inexpensive and simple dental anthropometric in-

Table 1. Shows t-test results for the five variables.

\begin{tabular}{|c|c|c|c|c|c|c|}
\hline Variables & Sex & $\mathrm{N}$ & Mean & Std. Deviation & $\mathrm{T}$-value & P-Value \\
\hline \multirow{2}{*}{ MD-Canine } & Male & 126 & 7.140 & 0.492 & \multirow{2}{*}{10.144} & \multirow{2}{*}{0.000} \\
\hline & Female & 137 & 6.519 & 0.276 & & \\
\hline \multirow{2}{*}{ MD- Upper right first molar } & Male & 129 & 10.147 & 0.601 & \multirow{2}{*}{3.342} & \multirow{2}{*}{0.001} \\
\hline & Female & 136 & 9.827 & 0.643 & & \\
\hline \multirow{2}{*}{ BL- Upper right first molar } & Male & 129 & 9.995 & 0.569 & \multirow{2}{*}{3.379} & \multirow{2}{*}{0.001} \\
\hline & Female & 136 & 9.718 & 0.518 & & \\
\hline \multirow{2}{*}{ MD- Upper right second molar } & Male & 129 & 9.344 & 0.612 & \multirow{2}{*}{3.262} & \multirow{2}{*}{0.001} \\
\hline & Female & 137 & 9.021 & 0.584 & & \\
\hline \multirow{2}{*}{ BL- Upper right second molar } & Male & 129 & 9.924 & 0.703 & \multirow{2}{*}{2.944} & \multirow{2}{*}{0.004} \\
\hline & Female & 137 & 9.655 & 0.593 & & \\
\hline
\end{tabular}


dications that can be used to determine sex within Syrian society. There are many similar articles in the medical literature that studied several races and societies, and most studies indicate the superiority of the lower canine over the rest of the teeth in determining sex [7]. Some studies attributed the increase in canine size in males than in females to the nature of male life which depends more on threat and violence than females, especially in primates [10]. Others attributed it to environmental factors and food habits [11], and some studies indicated the influence of genetic factors carried on the $\mathrm{Y}$ chromosome [12] on increasing canine size and hormonal factors on increasing sizes of male teeth [13].

(Filipovic et al., 2016) [14] found in his study on Serbian society that the upper and lower canines were the most important among teeth in sex determination, in another study conducted by (Ayoub et al., 2014) [15] on Lebanese society included 54 males And 69 females aged between 18 and 25 years old, the results were statistically significant with regard to the measurements of the lower canines without preference between left and right ones. The mean measure of the MD width of left canine in males was $7.187 \mathrm{~mm}$ in Ayob study, close to what was in our study $(7.136 \mathrm{~mm})$, and it was $6.541 \mathrm{~mm}$ in females while it was $6.519 \mathrm{~mm}$ in our study.

Most studies gave statistically significant results in dental sex indicators, but the accuracy of sex prediction varied between these studies, reaching 88\% in (Narang et al., 2015) [6] and decreased to $61 \%$ in (Yadav et al., 2015) [16].

Numerous studies found that the lower canine has a distinct value in determining sex $[17,20]$, others found the upper canine is more valuable $[21,22]$.

The results of our study differed with (Silva et al., 2016) [23], which indicated that there were no significant differences between males and females, and this difference can be attributed to the ages of individuals in Silva's sample as their sample included individuals in the fourth decade compared to younger individuals in our study. Because the loss of dental enamel as a result of nutritional habits and environmental factors is smaller in the younger age groups, so the MD width of the canine is subject to decrease with age.

This study also differed with two studies conducted in southern China (Yuen et al., 1997) [24] and Nepal (Acharya et al., 2007) [25], The results were contrary in both studies (Reverse dimorphism), which means that the female teeth were unexpectedly larger than the male teeth, and this may be due to the differences between human races.

In our study, we used dental casts according to (Hunter and Priest 1960) [26] standards, where the examiner took his measurements in a well-lit room and used a digital vernier caliper with a precision up to $0.01 \mathrm{~mm}$. This technique provides high control and direct vision compared to inside-mouth tecknique, any way (Kaushal et al., 2003) [27] showed no differences between measurements taken from dental casts compared to those taken directly inside the mouth.

\section{Conclusion}

This study showed that the sizes of some teeth in the Syrian so- ciety can carry an important indication in sex determination and thus help in the process of identifying human remains. There are few forensic studies for Eastern Mediterranean societies which living in armed conflict like Syria, and this is what gives this study its importance.

\section{References}

[1]. Kanthem RK, Guttikonda VR, Yeluri S, Kumari G. Sex determination using maxillary sinus. J Forensic Dent Sci.2015; 7(2):163-7.Pubmed PMID: 26005308.

[2]. De oliveraGamba T, Alves MC, Haiter-Neto F. Mandibular sexual dimorphism analysis in CBCT scans. J Forensic Leg Med.2016;38:106-110.Pubmed PMID: 26773251.

[3]. Stewart TD. Medico-legal aspects of the skeletonI. Age, sex, race and stature. Am J Phys Anthropl.1948;6(3):315-321.Pubmed PMID: 18884224.

[4]. RishabhKapila, K.S. Nagesh,Asha R. Iyengar,SushmaMehkri. Sexual Dimorphism in Human Mandibular Canines: A Radiomorphometric Study in South Indian Population. J Dent Res Dent Clin Dent Prospect.2011; 5(2):51-54.Pubmed PMID: 23019509.

[5]. Kieser JA, Groeneveld HT. The unreliability of sex allocation based on human odontometric data. J Forensic Odontostomatol.1989;7(1):1-12.Pubmed PMID: 2635185.

[6]. Ramandeep Singh Narang, Adesh S. Manchanda, Balwinder Singh. Sex assessment by molar odontometrics in North Indian population. J Forensic Dent Sc.2015; i7(1):54-58. Pubmed PMID: 25709321.

[7]. Pratapiene M, Cicciù M, Juodzbalys G. Caninesmesiodistal measures as the key to sex prediction: a systematic review and meta-analysis. Minerva Pediatr.2016;68(4):288-98.Pubmed PMID: 26154527.

[8]. Hilson S, Fitz Gerald C, FlinnH.Alternative dental measurements: Proposals and relationships with other measurements. Am J PhysAnthropol. 2005;126(4):413-26.Pubmed PMID: 15386233.

[9]. Nathan MD, Sakthi DS.Dentistry and Mass Disaster - A Review. J ClinDiagn Res.2014; 8(7): ZE01-ZE03. Pubmed PMID: 25177658.

[10]. Osborne RH, Horowitz SL, De George FV.Genetic variation in tooth dimensions: a twin study of the permanent anterior teeth. Am J Hum Genet.1958;10(3):350-6. Pubmed PMID: 13571223.

[11]. Lew KK, KengSB.Anterior crown dimensions and relationship in an ethnic Chinese population with normal occlusions. AustOrthod J.1991;12(2):1059. Pubmed PMID: 1843792.

[12]. McLaren A.Sex determination. What makes a man a man?. Nature.1990;346(6281):216-7.Pubmed PMID: 2374582.

[13]. Garn SM, Lewis AB, Kerewsky RS. The relationship between sexual dimorphism in tooth size and body size as studied within families. Arch Oral Biol. 1967;12(2):299-301.Pubmed PMID: 5228193.

[14]. Filipovic G, Kanjevac T, Cetenovic B, Ajdukovic Z, Petrovic N. Sexual Dimorphism in the Dimensions of Teeth in Serbian Population. Coll Antropol.2016;40(1):23-8.Pubmed PMID: 27301233.

[15]. Ayoub F, Shamseddine L, Rifai M, Cassia A, Diab R, Zaarour I, et al. Mandibular canine dimorphism in establishing sex identity in the Lebanese population. Int J Dent.2014;2014:235204. Pubmed PMID: 24672548.

[16]. Yadav AB, Angadi PV, Yadav SK. Sex assessment efficacy of permanent maxillary first molar cusp dimensions in Indians. ContempClin Dent.2015;6(4):489-495.Pubmed PMID: 26681853.

[17]. IqbalR, ZhangS, MiC. Reliability of mandibular canine and mandibular canine index in sex determination:A study using Uyghur population. J Forensic Leg Med.2015;33:9-13.Pubmed PMID: 26048489.

[18]. Kiran CS, Ramaswamy P, Swathi E, Smitha B, SudhakarS.Discriminant canine index - a novel approach in sex determination. Ann Stomatol (Roma).2015;6(2):43-6.Pubmed PMID: 26330903.

[19]. Paramkusam G, Nadendla LK, Devulapalli RV, PokalaA.Morphometric analysis of canine in gender determination: revisited in India. Indian J Dent Res.2014;25(4):425-9.Pubmed PMID: 25307902.

[20]. Agrawal A, Manjunatha BS, Dholia B, Althomali Y. Comparison of sexual dimorphism of permanent mandibular canine with mandibular first molar by odontometrics. J Forensic Dent Sci.2015;7(3):238-43.Pubmed PMID: 26816466.

[21]. Sravya T, Dumpala RK, Guttikonda VR, Manchikatla PK, Narasimha VC. Mesiodistalodontometrics as a distinguishing trait: A comparative preliminary study. J Forensic Dent Sci.2016;8(2):99-102.Pubmed PMID: 27555727.

[22]. Pandey N, Ma MS.Evaluation of sexual dimorphism in maxillary and mandibular canine using mesiodistal, labiolingual dimensions, and crown height. Indian J Dent Res.2016;27(5):473-476.Pubmed PMID: 27966502.

[23]. Silva AM, Pereira ML, Gouveia S, Tavares JN, Azevedo Á, Caldas IM. A 
new approach to sex estimation using the mandibular canine index. Med Sci Law.2016;56(1):7-12.Pubmed PMID: 25802199.

[24]. Yuen KK, So LL, Tang EL.Mesiodistal crown diameters of the primary and permanent teeth in southern Chinese: A longitudinal study. Eur J Orthod.1997;19(6):721-31.Pubmed PMID: 9458605.

[25]. Acharya A, MainaliS.Univariate sex dimorphism in the Nepalese dentition and the use of discriminant functions in gender assessment. Forensic Sci
Int.2007;173(1):47-56.Pubmed PMID: 17320321.

[26]. Hunter WS, Priest WR. Errors and discrepancies in measurement of tooth size. J Dent Res. 1960 Mar-Apr;39:405-14..Pubmed PMID: 14405477.

[27]. Kaushal S, Patnaik VVG, Agnihotri G.Mandibular canines in sex determination. J AnatSoc India.2003;52(2):119-124. 